\title{
Scopolamine effects on suppression of operant responding
}

\author{
LARRY P. GONZALEZ and HAROLD L. ALTSHULER \\ Neuropsychopharmacology Research Section, Texas Research Institute of Mental Science \\ and Department of Pharmacology, Baylor College of Medicine
}

Texas Medical Center, Houston, Texas 77030

\begin{abstract}
Three experiments are reported which examined the behavioral effects of pharmacological antagonism of cholinergic transmission. Subjects were trained in one of three tasks, each requiring inhibition of responding. The effects of scopolamine hydrobromide $(.4 \mathrm{mg} / \mathrm{kg})$ were compared to those of saline on performance of these tasks. Scopolamine did not alter foodreinforced responding on a variable interval (VI) schedule, nor did it affect the development of a conditioned emotional response. Incorrect responding in a discrimination task significantly increased, however, with scopolamine treatment. The results of these experiments are interpreted as contradicting hypotheses that central cholinergic systems mediate response suppression, and suggest their involvement in stimulus selection or discrimination.
\end{abstract}

Carlton $(1963,1968)$ suggested the presence of a central system of cholinergic neurons which mediates suppression of behavioral responding. Anticholinergic drugs have sometimes been reported to prevent or alter response habituation (Avis \& Pert, 1974; Carlton, 1968) and the extinction of responding (Glow \& Rose, 1966; Glow, Rose, \& Richardson, 1966; Russell, Watson, \& Frankenhauser, 1961); both responses involve a reduction in responding in the absence of reinforcement. Spontaneous alternation is decreased by cholinergic antagonists (Anisman \& Kokkinidis, 1975; Kokkinidis \& Anisman, 1976; Leaton \& Utell, 1970), even when nonalternating responses are punished (Bureš, 1968). Cholinergic antagonists are also reported to alter operant responding on fixed-interval schedules of reinforcement which are characterized by low responding just after reinforcement, followed by accelerated responding. Cholinergic blockers are reported to eliminate the period of low responding (Boren \& Navarro, 1959; Herrnstein, 1958; McKim, 1974).

Other investigators, however, have observed no effect of anticholinergic treatment on habituation of acoustic startle responses (Payne \& Anderson, 1967; Warburton \& Groves, 1969; Williams, Hamilton, \& Carlton, 1974) or on spontaneous alternation (Bureš, 1968). In addition, the effects of cholinergic antagonists on fixed-interval operant responding have sometimes been attenuated by the addition of exteroceptive stimuli which signal the availability of reinforcement (Laties \& Weiss, 1966; Weiss \& Heller, 1969).

L. P. Gonzalez' present address: Behavioral Neuropharmacology Section, Division of Biological Psychiatry, Department of Psychiatry, Box 3870, Duke University Medical Center, Durham, North Carolina 27710.
These studies suggest that the effects of cholinergic drugs on behavior may be task specific, and that cholinergic systems may not be involved in the mediation of general response suppression mechanisms. The present study examines the effects of scopolamine hydrobromide, a potent anticholinergic agent, on three different behavioral tasks, each requiring suppression of responding.

\section{EXPERIMENT 1: EFFECTS OF SCOPOLAMINE ON VI 60-SEC PERFORMANCE}

Operant conditioning techniques provide a particularly useful method for studying the behavioral effects of drugs (McMillan \& Leander, 1976). Reinforcement on a variable-interval (VI) schedule, in particular, generates a very stable response rate which is sensitive to drugs that alter central nervous system activity. Amphetamines, for example, are reported to increase response rate on a VI schedule at moderate doses (Segal, 1962; Thompson \& Corr, 1974), while pentobarbital decreases response rate (Hanson, Witoslawski, \& Campbell, 1967). The following experiment was performed to determine the effects of the cholinergic blocker scopolamine hydrobromide on VI response rate.

\section{Method}

Subjects. Ten male Sprague-Dawley rats (275-325 g), obtained from Simonsen Laboratories, were used in this study. The animals were maintained for at least 7 days in the same conditions of environment, diet, and daily handling before any experimental treatment. During the course of the study, the animals were housed in individual stainless steel cages with free access to water. Food intake was restricted by daily adjustments in feeding so as to maintain body weight at $85 \%$ of free-feeding weight. 
Apparatus. The training equipment consisted of five operant chambers (Scientific Prototype, Model A-100) and associated programming equipment (Grason-Stadler 1200 series). Each chamber was equipped with two identical levers, mounted on a single wall of the chamber, with a brass food tray positioned between the levers. The operant chambers were enclosed in sound-attenuating chambers equipped with fans, to provide air circulation and to mask external noise, and a $7-\mathrm{W}$ house lamp, to provide illumination. Data were collected in the form of cumulative records.

Procedure. Training began when subject weights stabilized at $85 \%$ of their free-feeding weights. The subjects then received $1-\mathrm{h}$ training sessions daily for the duration of the experiment. During the first session, 45-mg Noyes food pellets (Standard Formula) were delivered to the food tray, noncontingent upon the subject's behavior, on a variable-interval schedule of $60 \mathrm{sec}$ (VI $60 \mathrm{sec}$ ). At the same time, a continuous reinforcement schedule (CRF) was also in effect such that every response on the right-hand lever was reinforced with a food pellet (responding on the left lever had no consequence during this experiment).

Noncontingent food delivery was discontinued after the first session, with the CRF schedule remaining in effect for the next two sessions. During the fourth session, responding was reinforced according to a VI 15-sec schedule. The interval was increased to $30 \mathrm{sec}$ and then $60 \mathrm{sec}$ during the fifth and sixth sessions and maintained at $60 \mathrm{sec}$ during the seventh session.

Thirty minutes prior to the next experimental session, five subjects received intraperitoneal (IP) injections of saline $(1 \mathrm{cc} / \mathrm{kg})$ and five received IP injections of scopolamine hydrobromide $(.4 \mathrm{mg} / \mathrm{kg})$. This dose of scopolamine is above the threshold for producing a significant decrease in total brain ACh (Domino \& Domino, 1976; Pazzagli \& Pepeu, 1964) and has been reported to significantly affect various forms of learned behavior, including impairment of one-way avoidance acquisition (Domino \& Domino, 1976), retention of a maze task (Pazzagli \& Pepeu, 1964), and acquisition and retention of passive avoidance (Meyers, 1965). Injections were administered $30 \mathrm{~min}$ prior to the session, because the maximum effects of scopolamine in impairing avoidance performance (Herz, 1968) and in reducing total brain levels of $\mathrm{ACh}$ (Giarman \& Pepeu, 1964; Pazzagli \& Pepeu, 1964) are reported to occur between 30 and $90 \mathrm{~min}$ after injection. These conditions were reversed during the following experimental session. The performance of each subject on the VI 60 -sec schedule was observed during these two sessions.

During each experimental session, the occurrence of responses on the right (reinforced) lever and on the left (nonreinforced) lever was recorded on totaling counters; responses on the reinforced lever were also recorded on a cumulative recorder.

\section{Results and Conclusions}

By the seventh training session, the response rates of all of the subjects had stabilized on the VI $60-\mathrm{sec}$ schedule. As determined by an analysis of variance with repeated measures, the administration of scopolamine hydrobromide did not significantly $(p>.05)$ change the rate of responding on the reinforced lever. The mean $( \pm S D)$ rates of responding on this lever were $21.57 \pm 7.74$ responses/min after saline injection and $21.65 \pm 9.00$ responses $/ \mathrm{min}$ after scopolamine. Figure 1 presents the cumulative records obtained

\section{VI-60" PERFORINANGE}
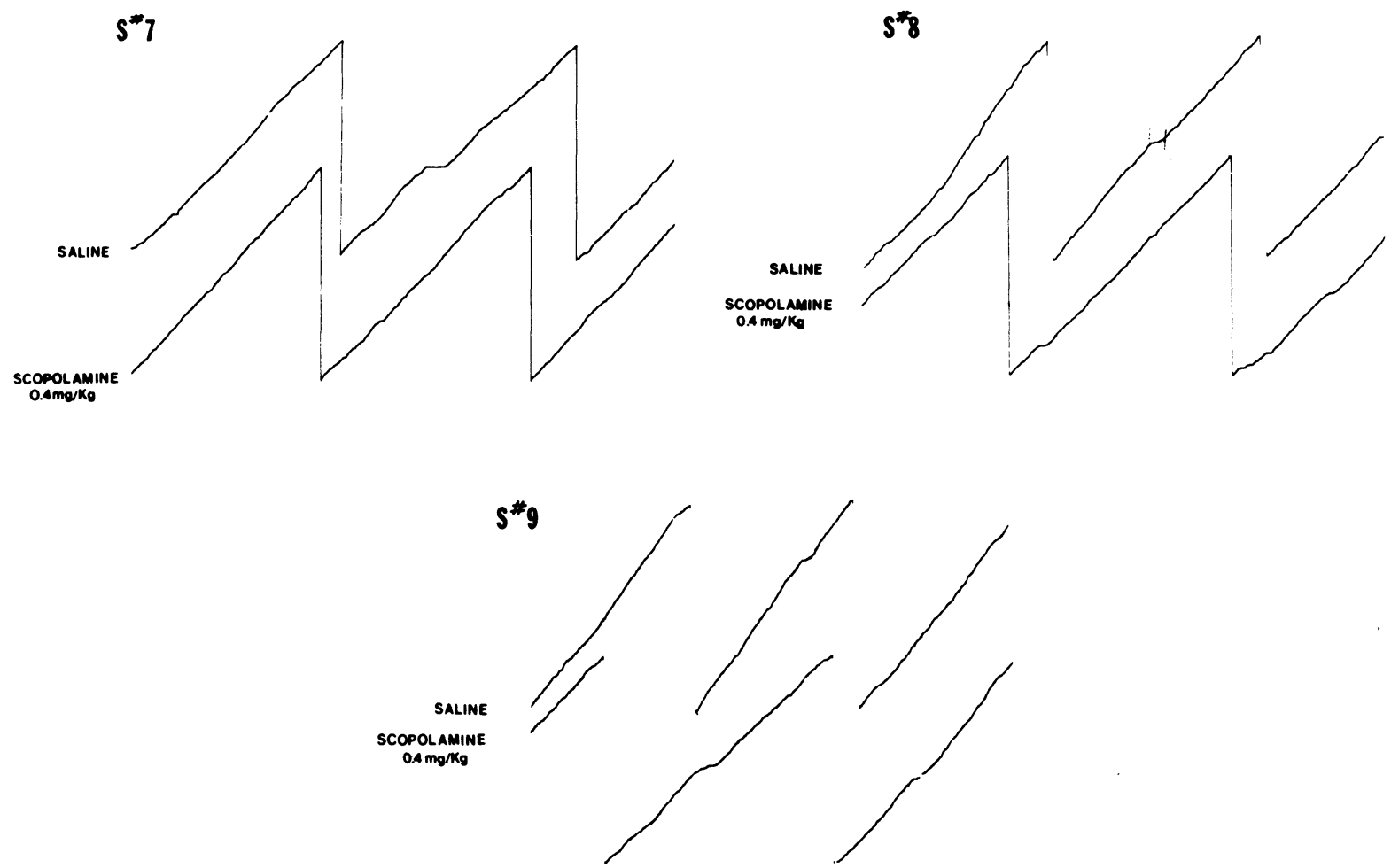

Figure 1. Cumulative records of correct responding for Subjects 7,8 , and 9 following intraperitoneal injections of either saline (upper trace of each pair) or $.4 \mathrm{mg} / \mathrm{kg}$ scopolamine (lower trace of each pair). The slope of each trace gives an indication of response rate. 
from several subjects, comparing responding during a saline and during a scopolamine session.

Responding on the nonreinforced lever accounted for less than $1 \%$ of the total responding on any experimental session (mean $\pm \mathrm{SD}=.47 \pm .67$ responses/ min following saline, and $.11 \pm .20$ responses $/ \mathrm{min}$ following scopolamine). Nonreinforced responding did not change significantly $(p>.05)$ with the administration of saline or scopolamine.

These results are contradictory to suggestions that cholinergic systems are involved in the inhibitory control of nonreinforced responses (Carlton, 1963) and of both competing and dominant responses (Warburton, 1972). In either case, correct and incorrect responding would be expected to increase during performance on a VI reinforcement schedule. At a dose which reduces total brain ACh (Domino \& Domino, 1976; Pazzagli \& Pepeu, 1964), increases spontaneous motor activity (Brimblecombe \& Buxton, 1971; Harris, 1961), and impairs performance in a variety of behavioral tasks (Longo, 1966), scopolamine did not affect VI performance.

\section{EXPERIMENT 2: \\ SCOPOLAMINE AND DEVELOPMENT OF A CONDITIONED EMOTIONAL RESPONSE}

In 1941 (Estes \& Skinner, 1941), a technique was reported for the suppression of ongoing operant behavior through the presentation of a stimulus that was paired with shock. The paradigm (cf. Beecroft, 1967) has come to be called conditioned suppression or the conditioned emotional response (CER).

Elevated levels of acetylcholine have been observed in the brains of rats killed during performance of a CER (Hingtgen, Smith, Shea, Aprison, \& Gaff, 1976). While this result is only correlational, it suggests the involvement of cholinergic systems in response suppression.

Anticholinergic drugs might be expected to impair development of the CER. Several investigators (Phillips \& Lowe, 1975; Vogel, Hughes, \& Carlton, 1967), using highly modified techniques for the development of the CER, have reported that neither atropine nor scopolamine impair CER development. Miczek (1973) reported similar results using the original Estes-Skinner procedure. In all of these studies, however, animals were trained and tested in different drug states: CER training was conducted following drug injection, with testing in the nondrug state in the first two studies; Miczek employed the reverse procedure, training nondrugged but testing drugged. Such designs do not permit a distinction between the effects of drugs on response acquisition and performance and effects on memory retrieval. Changes in drug state have been observed to produce a dissociation of learning (Thompson \& Pickens, 1971), and scopolamine has been reported to produce statedependent learning in some tasks (Gruber, Stone, \& Reed, 1967; Oliverio, 1968). Berger and Stein (1969) and Evans and Patton (1968) have, in fact, presented data which suggest that scopolamine can cause a dissociation of CER learning when training and testing occur in different drug states.

The following study was performed to determine the effects of scopolamine administration on development of behavioral suppression in the original CER paradigm (Estes \& Skinner, 1941), without changes in drug state.

\section{Method}

Subjects. Ten male Sprague-Dawley rats (275-325 g) were obtained from Simonsen Laboratories for use in this study. Housing and maintenance were as in the previous experiment.

Apparatus. The five operant chambers described previously were used. Sonalert tone generators $(2,900 \mathrm{~Hz})$ were added to each chamber to serve as a conditioned stimulus (CS), and the stainless steel grid floors were connected to a BRS/Foringer shock generator so that $.8 \mathrm{~mA}$ of scrambled ac shock (the unconditioned stimulus, UCS) could be delivered to the feet of a subject.

Procedure. The training procedure was identical to that used in Experiment 1. The subjects were trained during the first seven sessions to leverpress on a VI $60-\mathrm{sec}$ schedule as in the previous study; responding on the left lever was never reinforced.

In Sessions 8 and 9, the CS (3-min-duration, 2,900-Hz tone). was presented four times during each session, with an interstimulus interval (ISI) of $15 \mathrm{~min}$. The UCS (.5-sec, .8-mA ac shock) was not presented during these sessions. During the next eight experimental sessions, conditioned emotional response (CER) training was conducted. These sessions consisted of four CS presentations, with an ISI of $15 \mathrm{~min}$, paired with four UCS presentations. The UCS was presented during the last $.5 \mathrm{sec}$ of CS presentation.

During CER training, the subjects were divided into two groups of five subjects each. One group received a saline injection $(1 \mathrm{cc} / \mathrm{kg}$, IP) $30 \mathrm{~min}$ prior to each training session; the second group received a scopolamine injection $(.4 \mathrm{mg} / \mathrm{kg}$, IP) $30 \mathrm{~min}$ before each session.

Data were collected in terms of a suppression ratio (SR) for each session. The SR was determined as the ratio of the number of responses during the 3-min CS period and the number of responses during both the CS period and the 3-min interval preceding the CS.

\section{Results and Conclusions}

The mean suppression ratios for each group across sessions are presented in Figure 2. Both groups, those treated with saline and those with scopolamine, show the development of a CER. This is indicated by a significant change in suppression ratio across training sessions for both groups, as determined by a Friedman two-way analysis of variance $\left(\chi^{2} \mathrm{r}=58.9, \mathrm{df}=7\right.$, $p<.001)$. Group differences were tested for significance at each training session with the Mann-Whitney $\mathrm{U}$ test. Saline-treated subjects did not differ significantly $(p>.05)$ from scopolamine-treated subjects at any session.

A possible explanation of the results obtained in this study is that behavioral tolerance may have developed to the effects of scopolamine, resulting in a 


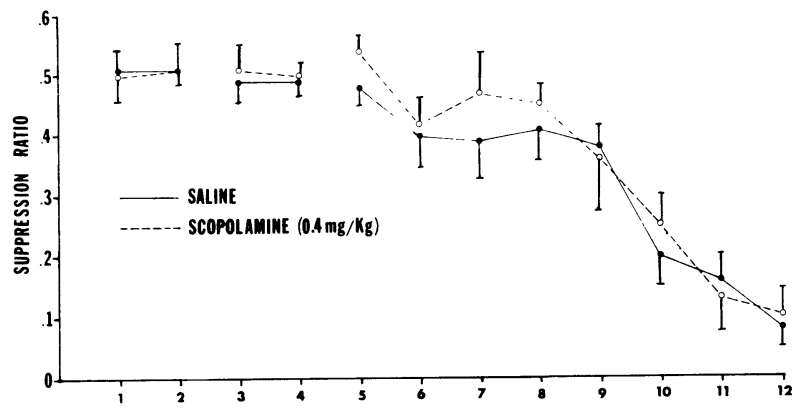

CER TRAINING SESSION

Figure 2. Mean suppression ratios for saline $(n=5)$ and scopolamine $(n=5)$ groups. During Sessions 1 and 2, neither the $C S$ nor the UCS was presented; the CS was presented alone during Sessions 3 and 4. During Sessions 5 through 12, the CS and UCS were both presented. Bars indicate the standard error of the mean at each point.

lack of effect. While there have been some suggestions that tolerance may develop to the behavioral effects of scopolamine, animals have required up to 25 injections of scopolamine before the development of tolerance in a discrimination task (Florio, Bignami, \& Longo, 1969) and over 100 injections for tolerance in a fixed-interval leverpress task (Charney \& Reynolds, 1967). Florio et al. (1969) did not observe tolerance to the effects of scopolamine on exploratory behaviors, head noddings, or startle responses, and Frontali, Amorico, Acetis, and Bignami (1976) report no change in scopolamine effects on an active-passive discrimination task with repeated injections. Since animals in the present study received a total of only eight scopolamine injections, it is unlikely that tolerance development could account for the observed lack of effect. In addition, behavioral tolerance is generally observed to result in behavioral changes in the direction of restoring reinforcement-contingent responding. The development of response suppression with repeated scopolamine treatment in the present experiment is inconsistent with such a concept of learned tolerance.

The CER is a suppression of ongoing responding in the presence of a stimulus which has been paired with the presentation of an aversive stimulus. The results of this experiment indicate that scopolaminetreated animals can suppress responding during such a stimulus. Cholinergic systems do not appear to play a significant role in the development of response suppression which is necessary for expression of the CER, as evidenced by the data in this study.

\section{EXPERIMENT 3: EFFECTS OF SCOPOLAMINE ON DISCRIMINATED DRL PERFORMANCE}

Experiments 1 and 2 examined the effects of scopolamine treatment in behavioral tasks which permit- ted an examination of response suppression. Experiment 3 was performed to allow a comparison of the effects of scopolamine on both response suppression and discrimination performance. For such a comparison, the effects of scopolamine on discrimination performance were observed during responding on a DRL (differential reinforcement of low response rate) schedule of reinforcement.

\section{Method}

Subjects. The subjects in this study consisted of 10 male Sprague-Dawley rats (275-325 g) obtained from Simonsen Laboratories. Housing and maintenance were as in the previous experiments.

Apparatus. The five operant chambers described in Experiment 1 served as the training apparatus in this study. Each chamber was equipped with a $2,900-\mathrm{Hz}$ tone generator (Sonalert) during the experiment.

Procedure. The subjects received 1-h training sessions daily for the duration of this experiment. The first session consisted of noncontingent food pellet delivery on a VI 60 -sec schedule with a concurrent continuous reinforcement (CRF) schedule: every response on either of the two available levers was reinforced. Noncontingent pellet delivery was discontinued after this first session. Reinforcement was available on a CRF schedule during the next three training sessions, but responding on only one lever was reinforced. The reinforced lever was alternated during those three sessions to avoid the formation of a side preference.

Discrimination training was begun with the fifth training session. During this session, a $2,900-\mathrm{Hz}$ tone served as a discriminative stimulus for responding on the right lever $\left(S_{R}^{D}\right)$; responding on the left lever was not reinforced during the presentation of the tone. The absence of the tone served as a cue for responding on the left lever $\left(\mathrm{S}_{\mathrm{L}}^{\mathrm{D}}\right)$; right lever responses were not reinforced. The tone was presented on a VI 3-min schedule, with tone duration varying around a mean of $3 \mathrm{~min}$. The $S_{R}^{D}$ and $S_{L}^{D}$ were each present for a total of 30 min during each 1-h training session.

During this and the next session, responding on the lever appropriate to the $\mathrm{S}^{\mathrm{D}}$ was reinforced on a CRF schedule. On the seventh training session, the reinforcement contingency was changed to a DRL schedule (differential reinforcement of a low response rate). Under this schedule, only correct responses which were farther apart in time than a selected interval were reinforced. An interresponse time (IRT) shorter than the selected interval recycled the required no-response interval, as did a response on the incorrect lever.

Training began with a DRL .5-sec schedule and was gradually shifted to DRL $15 \mathrm{sec}$ over the next 14 sessions. The DRL 15-sec requirement was maintained during two additional sessions to insure that performance was stable on this schedule.

Following these experimental sessions, training continued as before with the discriminated DRL $15 \mathrm{sec}$ maintained as the schedule of reinforcement. On every third session thereafter, however, subjects were tested for the effects of either saline $(1 \mathrm{cc} / \mathrm{kg}$, IP) or scopolamine hydrobromide $(.4 \mathrm{mg} / \mathrm{kg}$, IP) pretreatment $30 \mathrm{~min}$ prior to the session. During this test session, the subjects were placed in the operant chambers for $10 \mathrm{~min}$, during which reinforcement was never available. Both $S_{R}^{D}$ and $S_{L}^{D}$ were presented equally during the test session, and correct and incorrect leverpresses under both conditions were recorded. This procedure allowed examination of both DRL and discrimination performance without the presentation of food reinforcement as a cue to correct performance. After this 10 -min test, the subjects were removed from the operant chambers and received no further treatment for the day. Treatments of either saline or scopolamine alternated between test sessions until each subject had been tested three times with each treatment. 


\section{Results and Conclusions}

Figure 3 presents the cumulative records of two subjects during both saline and scopolamine test sessions. These subjects are representative of the entire group in that their responding was well controlled by the stimulus conditions, with very little responding on the incorrect lever during the saline sessions. A repeated-measures analysis of variance was used to evaluate differences in responding following injection of saline or scopolamine. Scopolamine had very little effect on responding on the correct lever $(p>.05)$; a small and nonsignificant decrease in correct lever response rate sometimes occurred $(\bar{X}=2.24 \pm 1.08$ responses/min following saline; $\bar{X}=2.06 \pm 1.86$ responses/min following scopolamine). Responding on the incorrect lever, however, increased significantly $(\mathrm{p}<.001)$ following scopolamine $(\overline{\mathrm{X}}=.51 \pm .61 \mathrm{re}-$ sponses/min following saline; $\bar{X}=1.39 \pm .69$ responses/min following scopolamine). Changes in total (correct + incorrect) responding were not significant.

The results of this experiment are contrary to suggestions that cholinergic systems are involved in response suppression. Scopolamine administration did not alter the ability of subjects to respond on a DRL reinforcement schedule, although this schedule requires a very low response rate. Discrimination performance, however, was impaired by the administration of scopolamine. These results suggest that cholinergic mechanisms may function in the processing of sensory information or in processes related to stimulus and response discrimination.

\section{DISCUSSION}

The objective of the preceding studies was to determine if central cholinergic systems were involved in response suppression.

Results of the experiments presented in this paper examined the effects of .4-mg/ $\mathrm{kg}$ scopolamine hydrobromide in several behavioral tasks. The particular tasks used are sensitive to alterations in a subject's ability to withhold responding and thus to alterations in response suppression (Carlton, 1963; Grossman, 1972; McCleary, 1966). Although only a single dose of scopolamine was used in these studies, this dose produces significant alterations in central cholinergic function (Domino \& Domino, 1976; Longo, 1966; Pazzagli \& Pepeu, 1964). Since the dose-response curve for scopolamine is relatively flat for many response variables (e.g., ACh content, Giarman \& Pepeu, 1964; EEG alterations, Longo, 1966; discrimination performance, Warburton, 1975; and delayed spatial alternation, Heise, 1975), it is unlikely that the use of other doses would have provided any additional information in these studies.

Experiment 1 demonstrated that the cholingergic antagonist scopolamine hydrobromide $(.4 \mathrm{mg} / \mathrm{kg})$
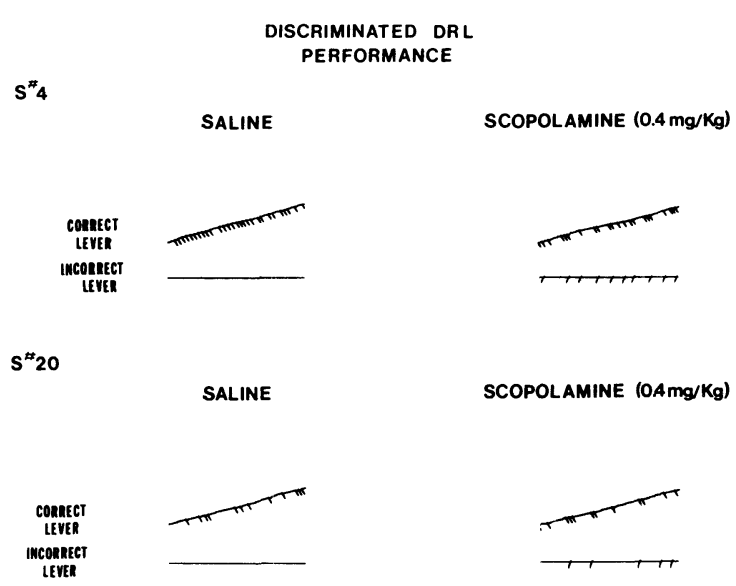

Figure 3. Response records of two subjects during saline and scopolamine sessions. The upper curve of each pair presents cumulative responses on the correct lever; downward slashes on this curve indicate correct schedule performance. Responses on the incorrect lever are indicated by downward slashes on the lower trace of each pair.

had no significant effect on responding on a variableinterval schedule of reinforcement. The dose of scopolamine used in this study produced behavioral arousal comparable to that observed following moderate doses of dl-amphetamine, but did not produce the increase in response rate observed with amphetamine (Segal, 1962; Thompson \& Corr, 1974). Impairment of response suppression mechanisms might have been expected to result in an increased operant rate, since a subject must inhibit responding to maintain the moderate rate produced on the variableinterval schedule. The finding that cholinergic blockade with scopolamine did not alter responding suggests that cholinergic systems are not necessary for response suppression.

This conclusion received further support in the results of Experiment 2. The conditioned emotional response (CER) represents a cessation of ongoing behavior in the presence of a stimulus previously associated with aversive stimuli. This learned suppression of behavior has been used extensively in the study of neural mechanisms of response inhibition and facilitation (McCleary, 1966). If cholinergic systems mediate response suppression, impairment of these systems by the administration of a cholinergic antagonist would be expected to prevent or inhibit acquisition of the CER. Scopolamine did not interfere with the development of a CER when administered before each training session. The acquisition of the CER resulted in a suppression of ongoing operant responding. This finding is contrary to a hypothesis of cholinergic involvement in response suppression. These results are in agreement with reports (Evans \& Patton, 1968; Vogel, Hughes, \& Carlton, 1967) that neither scopolamine nor atropine interfere with the develop- 
ment of a CER which results in the suppression of drinking behavior or of food-reinforced leverpressing (Miczek, 1973).

Examination of the effects of scopolamine on discriminated DRL performance in Experiment 3 allowed a comparison of the effects of cholinergic blockade on response suppression and on discrimination. The DRL reinforcement schedule requires that responding on the correct lever be maintained at a low rate. This would presumably require participation of mechanisms mediating the suppression of responding. Scopolamine administration did not affect total DRL responding and thus evidently does not interfere with response suppression mechanisms. Scopolamine did, however, impair discrimination performance, resulting in increased responding on the incorrect lever.

An interesting alternative hypothesis to that of response suppression proposes that cholinergic systems are not necessarily responsible for inhibition of response output, but rather mediate stimulus discrimination (Brown \& Warburton, 1971; Heise, 1975; Warburton \& Brown, 1971).

According to this view, anticholinergic drugs affect behavior as reported because they interfere with the discrimination of stimulus conditions. In two experiments designed to separate the effects of scopolamine on response inhibition and on stimulus discriminability (Brown \& Warburton, 1971; Warburton, 1972), it was concluded that scopolamine had little effect on response inhibition, but that it clearly reduced stimulus sensitivity. In this regard, it has also been reported that anticholinergic drugs reduce the amplitude of evoked potentials resulting from external stimuli (Green \& Aldous, 1971) and that activity in primary afferent pathways may be modulated by cholinergic inhibitory systems (Karczmar, 1975).

The studies reported in this paper do not support the hypothesis of cholinergic systems mediating response suppression. These results suggest that the neural processes which mediate stimulus discrimination may include important cholinergic elements.

\section{REFERENCES}

Anisman, H., \& Kokkinidis, L. Effects of scopolamine, d-amphetamine and other drugs affecting catecholamines on spontaneous alternation and locomotor activity in mice. Psychopharmacologia, 1975, 45, 55-63.

Avis, H. H., \& Pert, A. A comparison of the effects of muscarinic and nicotinic drugs on habituation and fear conditioning in rats. Psychopharmacologia, 1974, 34, 209-222.

Beecroft, R. S. Emotional conditioning. Psychonomic Monograph Supplement, 1967, 2, 45-72.

Berger, B. D., \& Stein, L. An analysis of the learning deficits produced by scopolamine. Psychopharmacologia, 1969, 14, 271-283.

Boren, J. J., \& Navarro, A. P. The action of atropine, benactyzine and scopolamine upon fixed-interval and fixed-ratio behavior. Journal of the Experimental Analysis of Behavior, $1959,2,107-112$.
Brimblecombe, R. W., \& Buxton, D. A. Behavioral actions of anticholinergic drugs. Progress in Brain Research, 1971, 35, 115-126.

Brown, K., \& W arburton, D. M. Attenuation of stimulus sensitivity by scopolamine. Psychonomic Science, 1971, 22, 297-298.

BurE ̌, J. The effect of physostigmine and atropine on some behavioral and electrophysiological function in rats. Progress in Brain Research, 1968, 28, 61-72.

Carlton, P. L. Cholinergic mechanisms in the control of behavior by the brain. Psychological Reviews, 1963, 70, 19-39.

Carlton, P. L. Brain acetylcholine and habituation. Progress in Brain Research, 1968, 28, 48-60.

Charney, N. H., \& Reynolds, G. S. Tolerance to the behavioral effects of scopolamine in rats. Psychopharmacologia, 1967, 11, 379-387.

Domino, K. B., \& Domino, E. F. Effects of scopolamine and methylscopolamine on acquisition and retention of rat one-way shuttle box behavior and total brain acetylcholine. Archives Internationales de Pharmacodynamie et de Therapie, 1976, 224, 248-257.

Estes, W. K., \& Skinner, B. F. Some quantitative properties of anxiety. Journal of Experimental Psychology, 1941, 29, $390-400$.

Evans, H. L., \& Patton, R. A. Scopolamine effects on a onetrial test of fear conditioning. Psychonomic Science, 1968, 11, 229-230.

Florio, V., Bignami, G., \& Longo, V. G. EEG patterns during the behavioral desensitization to scopolamine in rats. International Journal of Neuropharmacology, 1969, 8, 405-411.

Frontali, M., Americo, L., Acetis, L. De, \& Bignami, G. A pharmacological analysis of processes underlying differential responding: A review and further experiments with scopolamine, amphetamine, lysergic acid diethylamide (LSD-25), chlordiazepoxide, physostigmine, and chlorpromazine. Behavioral Biology, 1976, 18, 1-74.

Giarman, N. J., \& PEPeU, G. The influence of centrally acting cholinolytic drugs on brain acetylcholine levels. British Journal of Pharmacology and Chemotherapy, 1964, 23, 123-130.

GLow, P. H., \& Rose, S. Cholinesterase levels and operant extinction. Journal of Comparative and Physiological Psychology, 1966, 61, 165-172.

Glow, P. H., Rose, S., \& Richardson, A. The effects of acute and chronic treatment with di-isopropylfluoro-phosphate on the cholinesterase activities of some tissues in the rat. Austrian Journal of Experimental Biology, 1966, 44, 73-86.

Green, D. M., \& Aldous, F. A. B. The effects of anticholinergic drugs, chlorpromazine and LSD-25 on evoked potentials, EEG, and behavior. Progress in Brain Research, 1971, 36, 143-158.

Grossman, S. P. Cholinergic synapses in the limbic system and behavioral inhibition. Neurotransmitters, Research Publications of the Association for Research on Nervous and Mental Disorders, 1972, 50, 315-326.

Gruber, R. P., Stone, G. C., \& Reed, D. R. Scopolamineinduced anterograde amnesia. International Journal of Neuropharmacology, 1967, 6, 187-190.

Hanson, H. M., Witoslawski, J. J., \& Campbell, E. H. Drug effects in squirrel monkeys trained on a multiple schedule with a punishment contingency. Journal of the Experimental Analysis of Behavior, 1967, 10, 565-569.

HARris, L. S. The effects of various anticholinergics on the spontaneous activity of mice. Federation Proceedings, 1961, 20, 395.

Heise, G. A. Discrete trial analysis of drug action. Federation Proceedings, 1975, 34, 1898-1903.

Herrnstein, R. J. Effects of scopolamine on a multiple schedule. Journal of the Experimental Analysis of Behavior, 1958, 1, 351-358.

HERZ, A. Some actions of cholinergic and anticholinergic drugs on reactive behavior. Progress in Brain Research, 1968, 28, 73-85. 
Hingtgen, J. N., Smith, J. E., Shea, P. A., Aprison, M. H., \& GAFF, T. M. Cholinergic changes during conditioned suppression in rats. Science, 1976, 193, 332-334.

Karczmar, A. G. Cholinergic influences on behavior. Cholinergic Mechanisms. New York: Raven Press, 1975.

KoKk INIDIS, C., \& ANiSman, H. Interaction between cholinergic and catecholaminergic agents in a spontaneous alternation task. Psychopharmacology, 1976, 48, 261-270.

LAties, V. G., \& Weiss, B. Influence of drugs on behavior controlled by internal and external stimuli. Journal of Pharmacology and Experimental Therapeutics, 1966, 152, 388-396.

Leaton, R. N., \& Utell, M. J. Effects of scopolamine on spontaneous alternation following free and forced trials. Physiology \& Behavior, 1970, 5, 331-334.

LoNGo, V. G. Behavioral and electroencephalographic effects of atropine and related compounds. Pharmacological Reviews, 1966, 18, 965-996.

McCleary, R. A. Response-modulating functions of the limbic system: Initiation and suppression. In E. Stellar \& J. M. Sprague (Eds.), Progress in physiological psychology (Vol. 1). New York: Academic Press, 1966.

McKIM, W. A. The effects of scopolamine and physostigmine on fixed-interval behavior in the rat. Psychopharmacologia, 1974, 39, 237-244.

McMillan, D. E., \& Leander, J. D. Effects of drugs on schedule-controlled behavior. In S. D. Glick \& J. Goldfarb (Eds.), Behavioral pharmacology. St. Louis: Mosby, 1976.

Meyers, B. Some effects of scopolamine on a passive avoidance response in rats. Psychopharmacologia, 1965, 8, 111-119.

Micze K, K. A. Effects of scopolamine, amphetamine and benzodiazepines on conditioned suppression. Pharmacology, Biochemistry, and Behavior, 1973, 1, 401-411.

Oliverio, A. Effects of scopolamine on avoidance conditioning and habituation of mice. Psychopharmacologia, 1968, 12, 214-226.

Payne, R., \& Anderson, D. C. Scopolamine-produced changes in activity and in the startle response: Implications for behavioral activation. Psychopharmacologia, 1967, 12, 83-90.

Pazzagli, A., \& Pepeu, G. Amnesic properties of scopolamine and brain acetylcholine in the rat. International Journal of Neuropharmacology, 1964, 4, 291-299.
Phillips, K. C., \& Lowe, G. The suppression of behavior in rats by previous experience and electric shock and its antagonism by atropine. Psychopharmacologia, 1975, 42, 99-103.

Russell, R. W., Watson, R. H. J., \& Frankenhaeuser, M. Effects of chronic reductions in brain cholinesterase activity on acquisition and extinction of a conditioned avoidance response. Scandinavian Journal of Psychology, 1961, 2, 21-29.

Segal, E. F. Effects of dl-amphetamine under concurrent VI-DRL reinforcement. Journal of the Experimental Analysis of Behavior, 1962, 5, 105-112.

Thompson, D. M., \& CoRR, P. B. Behavioral parameters of drug action: Signalled and response independent reinforcement. Journal of the Experimental Analysis of Behavior, 1974, 21, 151-158.

Thompson, T., \& Pickens, R. Stimulus properties of drugs. New York: Appleton-Century-Crofts, 1971.

Vogel, J. R., Hughes, R. A., \& Carlton, P. L. Scopolamine, atropine, and conditioned fear. Psychopharmacologia, 1967, 10, 409-416.

WARBURTON, D. M. The cholinergic control of internal inhibition. In R. A. Boakes \& M. S. Halliday (Eds.), Inhibition and learning. London: Academic Press, 1972.

Warburton, D. M. Brain, behavior, and drugs. New York: Wiley, 1975.

Warburton, D. M., \& Brown, K. Scopolamine-induced attenuation of stimulus sensitivity. Nature, 1971, 230, 126-127.

Warburton, D. M., \& Groves, P. M. The effects of scopolamine on habituation of acoustic startle in rats. Communications in Behavioral Biology, 1969, 3, 289-293.

Weiss, B., \& Heller, A. Methodological problems in evaluating the role of cholinergic mechanisms in behavior. Federation Proceedings, 1969, 28, 135-146.

Williams, J. M., Hamilton, L. W., \& Carlton, P. L. Pharmacological and anatomical dissociation of two types of habituation. Journal of Comparative and Physiological Psychology, 1974, 87, 724-732.

(Received for publication July 25, 1978; revision accepted February 15, 1979.) 